The effects of facial attractiveness and trustworthiness in online peer-to-peer markets

Bastian Jaeger, Willem W. A. Sleegers, and Anthony M. Evans

Tilburg University

Mariëlle Stel

University of Twente

Ilja van Beest

Tilburg University

Draft version: 19 November 2018

This manuscript has been accepted for publication at the Journal of Economic Psychology

Word count: 7,890

Author Note

Bastian Jaeger, Willem W. A. Sleegers, Anthony M. Evans, and Ilja van Beest, Department of Social Psychology, Tilburg University, The Netherlands; Mariëlle Stel, Department of Psychology of Conflict, Risk and Safety, University of Twente, The Netherlands.

Correspondence concerning this article should be addressed to Bastian Jaeger, Department of Social Psychology, Tilburg University, P.O. Box 90153, 5000 LE Tilburg, The Netherlands. E-mail: bxjaeger@gmail.com 


\begin{abstract}
Online peer-to-peer markets, such as Airbnb, often include profile photos of sellers to reduce anonymity. Ert, Fleischer, and Magen (2016) found that more trustworthy-looking, but not more attractive-looking, Airbnb hosts from Stockholm charge higher prices for similar apartments. This suggests that people are willing to pay more for a night in an apartment if the host looks trustworthy. Here, we present a pre-registered replication testing how photo-based impressions of hosts' attractiveness and trustworthiness influence rental prices. We extend previous investigations by (a) controlling for additional features related to price (e.g., the apartment's location value), (b) testing for an influence of other host features, such as race and facial expression, and (c) analyzing a substantially larger sample of apartments. An analysis of 1,020 listings in New York City showed that more attractive-looking, but not more trustworthylooking, hosts charge higher prices for their apartments. Compared to White hosts, Black (but not Asian) hosts charge lower prices for their apartments. Hosts who smile more intensely in their profile photo charge higher prices. Our results support the general conclusion that people rely on profile photos in online markets, though we find that attractiveness is more important than trustworthiness.
\end{abstract}

Keywords: first impressions, peer-to-peer markets, trustworthiness, attractiveness 


\section{The effects of facial attractiveness and trustworthiness in online peer-to-peer markets}

In recent years, online peer-to-peer markets such as Airbnb, eBay, and Uber have become increasingly popular. While these markets offer new opportunities for the exchange of goods and services, they also present a unique challenge. Unlike sellers in traditional markets, sellers on peer-to-peer platforms are not registered business, but private citizens. Sellers' reputations are relatively uncertain and purchases can be perceived as more risky. As a consequence, establishing trust between sellers and customers is a key challenge for peer-to-peer platforms (Einav, Farronato, \& Levin, 2016). Building trust is particularly important for markets where the advertised service involves direct contact between consumers and sellers. On these platforms, sellers can provide services such as accommodation (e.g., Airbnb) or transport (e.g., Uber). However, people might be reluctant to enter the home or car of a complete stranger.

In order to facilitate trust between sellers and consumers, platforms include a variety of information about sellers. Next to review scores, profile photos are a common feature. Photos of sellers are meant to reduce anonymity, as well as facilitate identification offline (Guttentag, 2013). Critically, Ert and colleagues (2016) demonstrated that consumers on Airbnb use profile photos for more than identification-more trustworthy-looking hosts charge higher prices for similar apartments (i.e., when keeping other factors, such as review score and number of bedrooms constant). This suggests that consumers are willing to spend more on a night in an apartment when they perceive the host to be trustworthy. In other words, consumers seem to rely on first impressions based on sellers' profile photos when deciding which apartment to book. Here, we aim to replicate and extend Ert and colleagues' (2016; Study 1) findings by controlling for additional features related to price of apartments, by testing for an influence of other photobased impressions of hosts, such as race and facial expression, and by analyzing a substantially larger sample of apartments from a different city.

\section{Spontaneous trait inferences from faces}

People spontaneously infer personality characteristics of individuals solely based on their facial appearance (Todorov, Olivola, Dotsch, \& Mende-Siedlecki, 2015). Specifically, faces are evaluated on three dimensions: trustworthiness, dominance, and attractiveness (Sutherland et al., 2013, 2017). In line with other models of person and group perception (Abele \& Wojciszke, 2007; Fiske, Cuddy, Glick, \& Xu, 2002; see also Sutherland, Oldmeadow, \& Young, 2016), the first two dimensions on which faces are evaluated reflect evaluations of a target's intentions and 
abilities and are best captured by judgments of trustworthiness and dominance (Oosterhof \& Todorov, 2008). The third dimension reflects an evaluation of the target's attractiveness (Sutherland et al., 2013, 2017). People demonstrate some agreement in their face judgments (Hehman, Sutherland, Flake, \& Slepian, 2017). However, while people might share stereotypes about what, for example, a trustworthy person looks like, their impressions have limited accuracy at best (Olivola \& Todorov, 2010; Rule, Krendl, Ivcevic, \& Ambady, 2013; Todorov \& Porter, 2014).

\section{The influence of first impressions in peer-to-peer markets}

The widespread use of profile photos in online peer-to-peer markets and the spontaneous nature of face judgments raises the question whether photo-based impressions of sellers influence people's decision-making in these markets. Given the important role of trust in peer-topeer markets, one would expect sellers' perceived trustworthiness to play a central role (Guttentag, 2013; Ma, Hancock, Mingjie, \& Naaman, 2017). However, perceived attractiveness has also been shown to influence decision-making in situations that are not directly related to mate search. For example, attractive people receive more favorable treatment regarding personnel selection, career advancement, and wage distribution (Maestripieri, Henry, \& Nickels, 2017). Therefore, both perceived attractiveness and trustworthiness of sellers might inform consumers' decisions in peer-to-peer markets.

Several studies have compared the effects of trustworthiness and attractiveness in peerto-peer markets: Analyzing data from the crowdsourcing platform prosper.com, Duarte and colleagues (2012) found that more trustworthy-looking individuals are more likely to receive funding and receive more favorable interest rates; applicants' facial attractiveness was unrelated to their success. On the other hand, a similar study showed an advantage for attractive and creditworthy-looking borrowers (Ravina, 2012). ${ }^{1}$

In a similar vein, Ert and colleagues (2016; Study 1) investigated potential relationships between the perceived trustworthiness and attractiveness of Airbnb hosts and their apartment

\footnotetext{
${ }^{1}$ Ravina (2012) found no effect of perceived trustworthiness. However, trustworthiness and creditworthiness were highly correlated. In the context of lending decisions, it is thus not surprising that trustworthiness did not predict the outcomes of lending decisions when perceived creditworthiness was accounted for.
} 
rental prices. If consumers favor trustworthy-looking or attractive-looking hosts, then those hosts should on average be able to rent out their apartments at higher prices. Thus, a preference for hosts with a certain facial appearance can be quantified by predicting the price of listings with the facial appearance of hosts and other characteristics that might be valued by consumers and therefore influence the price of a listing (cf. Rosen, 1974). A price analysis of 175 listings in Stockholm showed that — controlling for a variety of other features such as review score and whether or not the apartment is shared with the host - more trustworthy-looking hosts charge higher prices for similar apartments. No effect of attractiveness on apartment prices was found. This suggests that consumers favor trustworthy-looking hosts and are willing to pay higher prices to stay with them. Ert and colleagues (2016) also found a negative interaction between hosts' perceived trustworthiness and attractiveness. The more attractive-looking the host, the smaller the positive effect of perceived trustworthiness. Moreover, in a follow-up experiment, Ert and colleagues (2016) manipulated the perceived trustworthiness of hosts and the variance in review scores. In this context, both perceived trustworthiness and attractiveness predicted participants' apartment preferences.

In sum, findings from previous studies show that people rely on trait inferences from faces when making decision in peer-to-peer markets, even when they have access to other relevant information such as credit history or review scores. However, the current evidence on whether people favor attractive-looking or trustworthy-looking sellers is mixed.

\section{The current study}

We present a pre-registered replication study that builds on the findings by Ert and colleagues (2016; Study 1). Our goal is to provide a more comprehensive analysis of the influence of facial cues on consumer decisions on Airbnb. Specifically, our study design contains three notable improvements. First, we control for additional features that have been shown to influence the price of Airbnb listings: the attractiveness of the apartment's location and whether the host is a so-called superhost (Edelman \& Luca, 2014; Gibbs, Guttentag, Gretzel, Morton, \& Goodwill, 2018). Airbnb uses the superhost designation to highlight hosts who pass certain quality checks such as a high response rate and a low cancellation rate. Second, we explore the influence of additional facial features (i.e., perceptions of the hosts' race, age, and smile intensity) on apartment prices. While the influence of some of these features has not been explored yet, they also represent potential confounds for the effects of attractiveness or 
trustworthiness. For example, smiling is positively related to perceived trustworthiness and attractiveness (Sutherland, Young, \& Rhodes, 2016). Controlling for these additional features provides a more robust test of the effects of facial attractiveness and trustworthiness on consumers' decisions. Third, we analyze a substantially larger sample of listings in New York City. Simonsohn (2015) suggested that, as a rule of thumb, replication studies should aim for a sample size that is at least 2.5 times larger than the original study. Here, we collect a sample of 1,020 listings, which is 5.8 times larger than the sample of the original study.

In addition to the analyses mentioned above, two exploratory analyses are presented. We investigate whether any effect of attractiveness is due to a beauty premium (i.e., more attractive hosts charging higher prices than hosts of average attractiveness), an ugliness penalty (i.e., less attractive charging less than hosts of average attractiveness), or both. This distinction is rarely tested in the literature and any effect of attractiveness is usually referred to as a beauty premium. Facial attractiveness is strongly correlated with perceptions of health (Jaeger, Wagemans, Evans, \& van Beest, 2018; Pazda, Thorstenson, Elliot, \& Perrett, 2016; Rhodes, 2006). Since people should be particularly motivated to avoid unhealthy (and therefore unattractive) individuals (Schaller \& Duncan, 2007; Zebrowitz, Fellous, Mignault, \& Andreoletti, 2003; Zebrowitz \& Rhodes, 2004), this account would predict an ugliness penalty, but not necessarily a beauty premium. Attractiveness biases might also be due to stereotypes linking attractiveness to more positive personality traits (Dion, Berscheid, \& Walster, 1972; Eagly, Ashmore, Makhijani, \& Longo, 1991). This account would predict a beauty premium, but not necessarily an ugliness penalty. Finally, we test for an effect of host race on apartment prices. This provides a replication of previous studies reporting that, compared to White host, Black and Asian hosts charge lower prices for similar apartments (Edelman \& Luca, 2014; Kakar, Franco, Voelz, \& Wu, 2016; Wang, Xi, \& Gilheany, 2015).

\section{Methods}

This study was pre-registered and all data and analysis scripts are available at the Open Science Framework (https://osf.io/3enh8/). We report how our sample size was determined, all data exclusions, and all measures in the study.

\section{Airbnb data}

We downloaded the New York City data set from the Inside Airbnb website (http://insideairbnb.com). This website features information on all Airbnb listings available in a 
specific city on a specific day. We selected New York City because it is one of the largest Airbnb markets worldwide. The dataset contains 40,227 Airbnb listings that were available on 3 December 2015. Next, we applied our pre-registered exclusion criteria. Our analysis focused on apartments (as opposed to, for example, guesthouses or bed and breakfasts), as they represent the majority of advertised listings (86.22\%). Apartments in which the rented room was shared with the host were also relatively rare (3.43\%) and therefore excluded. We only selected apartments that were available for at least 30 days in the previous year and that received at least five reviews. The host of the apartment had to have a verified identity, a profile photo available, and only one listing for rent. We extracted the zip code of each listings and recorded the median rent for an apartment in that neighborhood. ${ }^{2}$ This served as our measure of location value for each listing. Listings from zip codes with no available rent data were excluded (5,809 listings remaining). For the remaining listings, we downloaded the profile photos of hosts and selected the ones with only one depicted person in which the face of the host was clearly visible $(2,359$ listings remaining). We also downloaded the first photo of each listing which showed the apartment and selected the ones that give an impression of the inside living space (as opposed to, for example, photos of the New York City skyline; 2,110 listings remaining). Due to resource constraints, we randomly sampled 1,020 listings from the pool of remaining listings. Our analyses are based on this final sample of listings. For each listing, we recorded whether the entire apartment is rented out or shared with the host, whether the host is a superhost, the gender of the host ${ }^{3}$, number of bedrooms, median local rent, number of reviews, review score ${ }^{4}$, and the price per night.

${ }^{2}$ Rental data was accessed via www.trulia.com. Values indicate the median rental price for an apartment in a given zip code in January 2017.

${ }^{3}$ The first two authors independently coded the gender of all hosts by visually inspecting the profile photos. Agreement was at $100 \%$.

${ }^{4}$ Note that review scores are displayed to users on a scale from 1 to 5 stars (rounded in increments of 0.5 stars). The review score variable, which reflects the listing's average review, ranges from 20 (1 star) to 100 (5 stars). 


\section{Photo ratings}

We recruited 1,364 U. S. American workers from Amazon Mechanical Turk to rate 60 photos in exchange for 50 cents. We only recruited workers with approval rates above 90\%. Data from ten participants who reported only poor or basic proficiency in English and data from 13 participants who always indicated the same rating was discarded, leaving a final sample of 1,336 participants $\left(\mathrm{M}_{\mathrm{age}}=36.22, \mathrm{SD}_{\mathrm{age}}=11.60 ; 49.4 \%\right.$ female $)$. Participants were randomly allocated to one of three conditions, which determined what they rated the photos on: the trustworthiness of hosts $(n=446)$, the attractiveness of hosts $(n=443)$, or the attractiveness of apartments $(n=$ 447). Each participant rated the photos on only one trait in order to avoid consistency effects in ratings (cf. Penton-Voak, Pound, Little, \& Perrett, 2006). On average, each photo was rated by 26 participants $($ Min $=23$, Max $=30$ ), which should be sufficient to obtain stable average ratings (Hehman, Xie, Ofosu, \& Nespoli, 2018). Participants were unaware that the photos were taken from Airbnb.

In the two host photo conditions, participants saw a random subset of 60 profile photos and were asked to rate the depicted person's trustworthiness or attractiveness on an 11-point scale ranging from not at all [trait] (0) to extremely [trait] (11). Each participant rated the photos on only one trait dimension. In the apartment condition, participants saw a random subset of 60 apartment photos and were asked to rate the attractiveness of the apartment on a similar scale. Following the procedure of Ert and colleagues (2016), we calculated the median ratings as our indicators of perceived trustworthiness and attractiveness of the hosts and perceived attractiveness of the apartments.

\section{Photo classification}

Next, we used the Face++ application (Megvii Inc., http://www.faceplusplus.com) to classify the hosts' race, age, and smile intensity. Face++ is a commercial algorithm that has been used in previous research to extract various indicators from large numbers of face images (Edelman, Luca, \& Svirsky, 2017; Kosinski, 2017). For example, Edelman and colleagues (2017) used Face++ to classify the race of Airbnb guests. Face++ provides three race 
categorizations: White, Black, or Asian. ${ }^{5}$ Face++ also provides a continuous age estimate, and a smile intensity score that ranges from 0 to 100. Past studies have found high accuracy levels for the classification of race and age (An \& Weber, 2016; Jaeger, Sleegers, \& Evans, 2018; Rhue \& Clark, 2016).

\section{Results}

Price, median local rent, and number of reviews were $\log _{10}$-transformed due to their skewed distributions and all continuous variables were $\mathrm{z}$-standardized. We entered all variables into OLS regression models with price as the outcome variable.

\section{Descriptive statistics}

The price per night of listings ranged from $\$ 25$ to $\$ 1,500$ with a median price of $\$ 128.50$ $(M=\$ 150.62, S D=\$ 104.10)$. The perceived trustworthiness of hosts ranged from 2 to 9 on our 11 -point scale $(M=6.00, S D=1.06)$ and the same spread was observed for the perceived attractiveness of hosts $(M=5.58, S D=1.30)$. We found a small correlation between perceived trustworthiness and perceived attractiveness, $r(1,018)=.22, p<.001$. Face++ was unable to provide classifications for three hosts $(0.29 \%)$. Of the remaining 1,017 hosts, $73.84 \%$ were classified as White, $12.49 \%$ as Black, and $13.67 \%$ as Asian. There was a significant effect of race on perceived attractiveness, $F(2,1,014)=6.87, p=.001$, but not on perceived trustworthiness, $F(2,1,014)=1.84, p=.16$. Participants rated Black hosts $(M=5.21, S D=1.11)$ as less attractive than White hosts $(M=5.66, S D=1.28), t(186.9)=4.11, p<.001, d=0.39$, and marginally less attractive than Asian hosts $(M=5.51, S D=1.47), t(255.3)=1.88, p=.062, d=$ 0.50. We did not find a significant difference in attractiveness between White and Asian hosts, $t(186.9)=1.13, p=.26, d=0.10$. Age was negatively correlated with attractiveness, $r(1,015)=$ $.25, p<.001$, but there was no significant correlation with trustworthiness, $r(1,015)=-.0008, p=$ 98. Smile intensity was positively correlated with attractiveness, $r(1,015)=.13, p<.001$, and

\footnotetext{
${ }^{5}$ Naturally, the algorithm's classification is only based on superficial perceptual cues that can be extracted from a photograph, such as face shape and skin color. We do not claim that the algorithm's broad classification provides an accurate reflection of an individual's ethnic background. However, this is not a limitation in the current context as we were not interested in the influence of a hosts' actual race or ethnicity, but rather in their race category as perceived by consumers on the basis of a profile photo.
} 
with trustworthiness, $r(1,015)=.47, p<.001$. Descriptive statistics for all predictors can be found in Table 1 (for continuous variables) and Table 2 (for categorical variables). For ease of interpretation, we report descriptive statistics if unstandardized variables.

Table 1

Descriptive statistics for all continuous variables.

\begin{tabular}{lrrrrrr}
\hline \multicolumn{1}{c}{ Variable } & \multicolumn{1}{c}{ M } & \multicolumn{1}{c}{ SD } & \multicolumn{1}{c}{ Min } & \multicolumn{1}{c}{ Median } & \multicolumn{1}{c}{ Skew } \\
\hline Trustworthiness & 6.00 & 1.06 & 2.00 & 9.00 & 6.00 & -0.486 \\
Attractiveness & 5.58 & 1.30 & 2.00 & 9.00 & 6.00 & -0.105 \\
Price & 150.62 & 104.10 & 25.00 & $1,500.00$ & 128.50 & 4.322 \\
Apartment photo & 5.84 & 1.41 & 2.00 & 10.00 & 6.00 & -0.228 \\
Bedrooms & 1.08 & 0.61 & 0.00 & 4.00 & 1.00 & 1.502 \\
Median local rent & $4,517.69$ & $3,948.06$ & 650.00 & $45,000.00$ & $3,399.00$ & 4.771 \\
\# of reviews & 31.96 & 32.40 & 5.00 & 251.00 & 19.00 & 2.233 \\
Review score & 93.29 & 5.35 & 65.00 & 100.00 & 94.00 & -1.318 \\
Face++ smile & 57.98 & 36.59 & 0.14 & 99.83 & 69.53 & -0.311 \\
Face++ age & 43.08 & 10.21 & 12.00 & 72.00 & 44.00 & -0.098 \\
\hline
\end{tabular}


Table 2

Descriptive statistics for all categorical variables.

\begin{tabular}{llrr}
\hline Variable & \multicolumn{1}{c}{ Group } & N & $\%$ \\
\hline Entire apartment & No & 387 & 37.94 \\
Host gender & Yes & 633 & 62.06 \\
& Female & 529 & 51.86 \\
Superhost & Male & 491 & 48.14 \\
& No & 863 & 84.61 \\
Face++ race & Yes & 157 & 15.39 \\
& Black & 127 & 12.45 \\
& Asian & 139 & 13.63 \\
& White & 751 & 73.63 \\
& Undetected & 3 & 0.29 \\
\hline
\end{tabular}

\section{Confirmatory analyses}

In accordance with the approach by Ert and colleagues (2016), we conducted multiple regression analyses to predict the price of listings with the hosts' perceived trustworthiness and attractiveness, while controlling for other features of the host and the listing (see Table 3). We did not find an effect of host trustworthiness, $\beta=-0.0036, S E=0.0047, t(1,010)=-0.76, p=.45$, 95\% CI [-0.013, 0.0057] (Model 1). However, we did find a positive effect of host attractiveness, $\beta=0.011, S E=0.0048, t(1,010)=2.34, p=.020,95 \%$ CI $[0.0018,0.021]$ (Model 2). These effects did not change when host attractiveness and trustworthiness were entered simultaneously into a model (Model 3). There was no significant interaction between host attractiveness and trustworthiness, $\beta=0.0075, S E=0.0042, t(1,008)=1.79, p=.074,95 \%$ CI $[-0.00074,0.016]$ (Model 4).

Thus, in contrast to Ert and colleagues (2016; Study 1), we did not find a main effect of perceived trustworthiness, or an interaction effect between trustworthiness and attractiveness. Instead, we found a main effect of attractiveness. Specifically, a one standard deviation increase in perceived attractiveness was associated with a $2.78 \%$ price increase. As a comparison, a one standard deviation increase in review score was associated with a $5.26 \%$ price increase and the 
presence of an additional bedroom (which can also be seen as a proxy for the apartment's size) was associated with a $15.66 \%$ price increase.

Table 3

The influence of facial trustworthiness and attractiveness on the price of Airbnb listings

\begin{tabular}{|c|c|c|c|c|}
\hline & Model 1 & Model 2 & Model 3 & Model 4 \\
\hline Trustworthiness & -0.004 & & -0.005 & -0.004 \\
\hline Attractiveness & & $0.011 *$ & $0.012 *$ & $0.013 * *$ \\
\hline $\begin{array}{l}\text { Trustworthiness* } \\
\text { attractiveness }\end{array}$ & & & & 0.008 \\
\hline Apartment rating & $0.054 * * *$ & $0.053 * * *$ & $0.053 * * *$ & $0.053 * * *$ \\
\hline Bedrooms & $0.063 * * *$ & $0.063 * * *$ & $0.063 * * *$ & $0.063 * * *$ \\
\hline Entire apartment & $0.246 * * *$ & $0.245 * * *$ & $0.245 * * *$ & $0.246 * * *$ \\
\hline Male host & -0.002 & 0.008 & 0.005 & 0.005 \\
\hline Superhost & 0.013 & 0.014 & 0.015 & 0.015 \\
\hline Median local rent & $0.077 * * *$ & $0.076 * * *$ & $0.076 * * *$ & $0.076 * * *$ \\
\hline \# of reviews & 0.001 & 0.002 & 0.002 & 0.002 \\
\hline Review score & $0.022 * * *$ & $0.022 * * *$ & $0.022 * * *$ & $0.022 * * *$ \\
\hline $\operatorname{adj} . \mathrm{R}^{2}$ & .636 & .637 & .637 & .638 \\
\hline
\end{tabular}

Next, we tested for potential interaction effects between the facial appearance of hosts and other characteristics of the hosts or their apartments. Physical attractiveness is valued more in women than men (Buss, 1989; Feingold, 1990) and financial benefits for more attractive individuals have been observed more consistently when women rather than men were the targets (Maestripieri et al., 2017). However, we found no interactions between the gender of the host and their perceived attractiveness, $\beta=0.0057, S E=0.0096, t(1,008)=0.59, p=.56,95 \%$ CI [0.013, 0.025], or their perceived trustworthiness, $\beta=-0.018, S E=0.0095, t(1,008)=-1.89, p=$ $.058,95 \%$ CI [-0.037, 0.00065]. We also tested for potential interaction effects between perceived attractiveness or trustworthiness and whether the entire apartment is rented out rather 
than shared with the host. It is likely that consumers who share the apartment have more direct contact with the host. They might therefore be more concerned with selecting a desirable host. However, we found no interaction between whether the entire apartment was offered (vs. shared with the host) and the host's perceived attractiveness, $\beta=-0.0016, S E=0.0096, t(1,008)=-0.17$, $p=.86,95 \% \mathrm{CI}[-0.02,0.017]$, or perceived trustworthiness, $\beta=-0.0077, S E=0.0091, t(1,008)$ $=-0.85, p=.40,95 \%$ CI $[-0.026,0.01] .^{6}$

\section{Exploratory analyses}

\section{Beauty premium vs. ugliness penalty.}

To test for independent effects of low and high attractiveness, we grouped hosts into three attractiveness categories: one standard deviation below average or lower $(n=204,20 \%)$, one standard deviation above average or higher $(n=253,24.80 \%)$, or in between $(n=563$, $55.20 \%$ ). Regressing price on attractiveness category (with average attractiveness as the reference group) revealed evidence for an ugliness penalty, but not a beauty premium (Table 4, Model 5): Low attractiveness was negatively related to price, $\beta=-0.031, S E=0.012, t(1,008)=-$ $2.60, p=.009,95 \%$ CI [-0.054, -0.0075], whereas we did not find evidence that high attractiveness was positively related to price, $\beta=0.0028, S E=0.011, t(1,008)=0.25, p=.80$, $95 \%$ CI $[-0.019,0.025]$. Specifically, relatively unattractive hosts charged $6.82 \%$ less for their listings.

The influence of race, age, and smile intensity. We also extended our analysis by including additional characteristics acquired through the Face++ algorithm, which was used to classify a host's race, age, and smile intensity based on their profile photo. Including race, age, and smile intensity in our regression model showed that, compared to White hosts, Black hosts charged significantly lower prices for their listings, $\beta=-0.046, S E=0.014, t(1,002)=-3.32, p<$ $.001,95 \%$ CI [-0.074, -0.019] (Table 4, Model 6). Specifically, Black hosts charged 10.09\% lower prices for similar apartments. We found no price difference between White and Asian hosts, $\beta=0.0025, S E=0.013, t(1,002)=0.19, p=.85,95 \%$ CI [-0.024, 0.029]. Furthermore,

\footnotetext{
${ }^{6}$ We repeated all analyses reported here with mean trustworthiness and attractiveness ratings, as opposed to median ratings, but no differences in results were found. In a similar vein, excluding six listings with prices that were three or more standard deviations above or below the mean logtransformed price led to qualitatively equivalent results.
} 
estimated age of the host was not associated with the price of their apartment, $\beta=0.0051, S E=$ $0.0048, t(1,002)=1.07, p=.28,95 \% \mathrm{CI}[-0.0042,0.014]$.

The smile intensity of the host was positively associated with rental price, $\beta=0.015, S E$ $=0.0051, t(1,002)=3.00, p=.003,95 \%$ CI $[0.0053,0.025]$. A one standard deviation increase in smile intensity was related to a $3.61 \%$ price increase. Crucially, we still found a positive effect of perceived attractiveness when controlling for these additional variables $\beta=0.011, S E=0.0050$, $t(1,002)=2.34, p=.019,95 \% \mathrm{CI}[0.0019,0.021]$, showing that the positive effect of perceived attractiveness is not due to the host's race, age, or smile intensity. We also found a negative effect of perceived trustworthiness $\beta=-0.012, S E=0.0053, t(1,002)=2.32, p=.021,95 \%$ CI [$0.023,-0.0019]$. 
Table 4

The influence of facial trustworthiness and attractiveness on the price of Airbnb listings when controlling for additional characteristics of the hosts.

\begin{tabular}{|c|c|c|}
\hline & Model 5 & Model 6 \\
\hline Trustworthiness & -0.006 & $-0.012 *$ \\
\hline Attractiveness & & $0.012 *$ \\
\hline Low Attractiveness & $-0.031 * *$ & \\
\hline High Attractiveness & 0.003 & \\
\hline Black host & & $-0.046 * * *$ \\
\hline Asian host & & 0.002 \\
\hline Host age & & 0.005 \\
\hline Smile intensity & & $0.015 * *$ \\
\hline Apartment rating & $0.053 * * *$ & $0.054 * * *$ \\
\hline Bedrooms & $0.063 * * *$ & $0.063 * * *$ \\
\hline Entire apartment & $0.246 * * *$ & $0.247 * * *$ \\
\hline Male host & 0.001 & 0.006 \\
\hline Superhost & 0.016 & 0.013 \\
\hline Median local rent & $0.076 * * *$ & $0.072 * * *$ \\
\hline \# of reviews (log) & 0.001 & 0.002 \\
\hline Review score & $0.022 * * *$ & $0.021 * * *$ \\
\hline adj. $R^{2}$ & .638 & .643 \\
\hline
\end{tabular}

\section{General Discussion}

We examined the relationship between perceived facial attractiveness and trustworthiness of Airbnb hosts and the price they are charging for their apartments. While some studies have shown that consumer decisions in online peer-to-peer markets are influenced by the attractiveness and trustworthiness of sellers, evidence on which trait is favored in sellers is mixed 
(Duarte et al., 2012; Ert et al., 2016; Ravina, 2012). Our analysis of 1,020 Airbnb listings in New York City revealed that more attractive-looking hosts charge $2.78 \%$ higher prices for similar apartments. We did not find that more trustworthy-looking hosts charge different prices. This suggests that consumers are willing to spend more on apartments that are offered by more attractive host.

Our results do not replicate findings by Ert and colleagues (2016; Study 1) who reported a positive effect of perceived trustworthiness, but not attractiveness, in a sample of 175 listings. It should be noted that our study differed from this previous investigation in a few notable ways. First, we controlled for additional factors related to the apartment (the attractiveness of the apartment's location) and the host (race, age, smile intensity, and whether they are a superhost) that could confound the relationship between photo-based impressions and the price of listings. Second, we analyzed a substantially larger sample $(n=1,020)$. Both should result in a more precise estimate of the influence of facial attractiveness and trustworthiness on apartment prices. Third, we analyzed Airbnb listings from New York City rather than Stockholm in order to be able to collect a larger sample. It is possible that trait preferences for Airbnb hosts vary across different countries or cities. In fact, the association between other host characteristics (e.g., the superhost designation) and apartment prices has been shown to differ across different cities (Gibbs et al., 2018). Although, we have no theory-based explanation regarding the relative importance of perceived attractiveness and trustworthiness in Airbnb hosts in New York City and Stockholm, future studies could explore if reliable differences in trait preferences exist.

Our findings converge with previous studies showing that trait inferences from faces can influence a variety of decisions (Maestripieri et al., 2017; Olivola, Funk, \& Todorov, 2014). Forming trait impressions from faces is a fast and intuitive process (Klapper, Dotsch, van Rooij, \& Wigboldus, 2016; Ritchie, Palermo, \& Rhodes, 2017; Willis \& Todorov, 2006). Given the prominent role of profile photos in online peer-to-peer market, it may thus not seem surprising that the facial appearance of hosts influences people's decision whom to stay with. Importantly, the effect of facial attractiveness was observed when controlling for other photo-based cues such as the host's gender, age, race, and facial expression. In sum, we conclude that impressions of attractiveness guide consumer decisions even when a myriad of other cues are available.

Examining the influence of these other cues, we found that Black hosts charge on average $10.09 \%$ less for their apartments. This in line with the price gap of approximately $12 \%$ reported 
by Edelman and Luca (2014). However, in contrast to previous studies that analyzed Airbnb listing in San Francisco, Oakland, and Berkeley (Kakar et al., 2016; Wang et al., 2015), we did not find that Asian hosts charge less for their apartments. We also found that hosts with more intense smiles charge 3.61\% higher rents for their apartments. Fagerstrøm and colleagues (2017) showed that participants were more motivated to explore an Airbnb listing's web page when the profile photo showed a smiling rather than a neutral host. Our results demonstrate that this preference for smiling hosts can also be observed in consumer's revealed preferences.

Why do consumers prefer to stay with attractive hosts? One explanation is that due to the critical importance of engaging with healthy partners, preferences for attractive individuals, consciously or unconsciously, spill over to situation that are not directly related to mate search (Maestripieri et al., 2017). Unattractive hosts might elicit avoidance motivations, which then spill over to consumer's apartment choices. In fact, similar effects of facial attractiveness on seemingly unrelated preferences have been observed for interest in scientific work (Gheorghiu, Callan, \& Skylark, 2017). This account is also supported by our current finding that the effect of attractiveness on apartment prices is driven by unattractive hosts charging lower prices, rather than by attractive hosts charging higher prices. Attractive individuals are seen as more healthy (Rhodes et al., 2007). Given the importance of avoiding unhealthy individuals (Schaller \& Duncan, 2007; Zebrowitz et al., 2003; Zebrowitz \& Rhodes, 2004), we would therefore expect the negative effect of low attractiveness to be stronger than the positive effect of high attractiveness (cf. Jaeger, Wagemans, et al., 2018; Pazda et al., 2016).

It is also possible that people consciously select attractive hosts because they believe that they will enjoy their stay with them more. For example, attractive people are believed to possess more positive personality traits (Dion et al., 1972; Eagly et al., 1991). While perceived trustworthiness did not predict apartment prices, people might value other traits such as sociability and rely on a host's attractiveness to infer their sociability. Do people actually have better stays with attractive hosts? We can test this by probing for a relationship between the attractiveness of hosts and their review score, which should reflect people's satisfaction with their stay. We do not find any evidence that people assign higher review scores to more attractive hosts, $r(1,018)=-.019, p=.54$.

Relatedly, if people consciously select attractive hosts out of sexual interest, we would expect a larger attractiveness effect when the apartment is shared and there is actual contact 
between guest and host. This prediction was not confirmed by our results either. In sum, the hypotheses that consumers consciously prefer attractive hosts due to sexual interest or that they derive pleasure from interacting with an attractive host is not supported by the current data. However, it should be noted that our study was not designed to test these different accounts directly and the results reported here should only be taken as preliminary evidence. Future studies need to address the exact reasons underlying consumers' reliance on attractiveness when deciding whom to stay with. For example, if mating motives really play a role, we would expect larger effects of attractiveness in opposite-sex, rather than same-sex interactions. More generally, future studies on the influence of attractiveness would benefit from testing for different effects of low and high (vs. average) attractiveness. Currently, this distinction is rarely made in the literature and any effect of attractiveness is referred to as a beauty premium (e.g., Berggren, Jordahl, \& Poutvaara, 2010; Gonzalez \& Loureiro, 2014; Hamermesh \& Biddle, 1994).

\section{Limitations}

A potential limitation of the current study is the use of price as a proxy for consumer preferences. In line with previous studies (e.g., Edelman \& Luca, 2014; Ert et al., 2016), we reasoned that, if consumers favor a particularly attractive-looking or trustworthy-looking host, then those hosts should be able to charge higher prices for their apartments (Malpezzi, 2008; Rosen, 1974). One requirement for such an analysis is that other factors, which are valued by consumers and thus drive the price, are controlled for. To this end, we included various characteristics of the apartment and the host in our models. This also allowed us to test the validity of our methodological approach. If price is determined by the presence or absence of features that are valued by consumers, then we would predict to find significant effects for features that should be strongly valued by people who are looking to rent an apartment on Airbnb. Indeed, the price of apartments was related to their size, review score, and location value. In other words, our results confirm the intuition that consumers would be willing to pay more for a larger apartment, for an apartment that received better reviews, or for an apartment that is located in a better neighborhood (see also Gibbs et al., 2018).

We also acknowledge that our work is correlation, which precludes us from making any causal claims. While experimental studies in the lab provide more opportunities to disentangle the unique effects of different factors, analyzing real-world data such as the prices of Airbnb listings has the advantage of revealing actual behavior in an ecologically valid environment. 
Ultimately, we believe that evidence from both inside and outside the lab is needed to provide a convincing test of the influence of facial features on decision-making (Baumeister, Vohs, \& Funder, 2007; Maner, 2016).

\section{Practical implications}

Next to demonstrating the effect of facial attractiveness using real-world data, our findings have implications for the design of online peer-to-peer platforms. Edelman and Luca (2014) — who were the first to find evidence of a price gap between White and Black hosts on Airbnb, a finding which we successfully replicated - suggested that photos should be omitted from platforms in order to prevent racial discrimination. We also show that consumers not only discriminate on the basis of race, but also attractiveness. These findings might prompt some hosts to remove their profile photos to guard themselves against any appearance-based discrimination. However, we would be careful in advising Black or unattractive hosts to delete their photos unilaterally. People are less motivated to explore a listing's web page if no photo is displayed (and other listings include photos; Fagerstrøm et al., 2017) and they generally value photos in trust-based economic exchange (Eckel \& Petrie, 2011; see also Heyes \& List, 2016). Thus, removing one's profile photo might actually result in a similar price penalty. Future studies should investigate how the presence or absence of a profile photo influences preferences for sellers in peer-to-peer markets.

Similar to Edelman and Luca (2014), we advise platforms such as Airbnb to regulate which information about sellers is provided (and at what time). Photos enable personal identification, which can facilitate initial trust between sellers and consumers. However, this information is not necessarily needed when consumers are browsing for apartments. Platforms could provide photos of sellers only at the moment a transaction has been made, or when users send initial inquiries to hosts about listings. This change would enable personal identification of sellers, but prevent consumers from engaging in appearance-based discrimination when selecting a rental location.

An alternative approach would be to increase the salience of objective rental information and decrease the salience of profile photos. Consumers pay more attention to information that takes up a lot of space (Wedel \& Pieters, 2007). Many platforms currently display profile photos very prominently, which makes the seller's appearance a particularly salient feature. Instead of showing profile photos in large size at the top of a listing's web page, they could be displayed in 
reduced size on a separate page, such as the seller's personal profile. For example, Airbnb's most recent web design, which was implemented at the end of 2016, features a large photo of the listing, while the size of the host's photo (but not the prominence of its position) was reduced. In general, more data is needed to systematically test the influence of profile photos on consumer behavior. Future studies could test whether less salient photos actually reduces appearance-based discrimination and whether providing photos only after a transaction has been made affects.

\section{Conclusion}

Our analysis of 1,020 apartments in New York City shows that more attractive-looking hosts charge higher prices for similar apartments, suggesting that consumers are willing to spend more on a night in an apartment if they are staying with a more attractive host. This effect was due to an ugliness penalty, rather than a beauty premium: Less attractive hosts charge lower prices whereas more attractive hosts do not charge higher prices. We did not replicate Ert and colleagues' (2016; Study 1) finding that the perceived trustworthiness of hosts influences apartment prices. However, we did replicate previous findings showing that Black hosts charge lower prices for their apartments (Edelman \& Luca, 2014). Taken together, our findings show that photo-based impressions guide consumer decisions in peer-to-peer markets. 


\section{References}

Abele, A. E., \& Wojciszke, B. (2007). Agency and communion from the perspective of self versus others. Journal of Personality and Social Psychology, 93(5), 751-63. https://doi.org/10.1037/0022-3514.93.5.751

An, J., \& Weber, I. (2016). \#greysanatomy vs. \#yankees: Demographics and hashtag use on twitter. In Proceedings of the 10th International Conference on Weblogs and Social Media (pp. 523-526).

Baumeister, R. F., Vohs, K. D., \& Funder, D. C. (2007). Psychology as the science of selfreports and finger movements: Whatever happened to actual behavior? Perspectives on Psychological Science, 2(4), 396-403. https://doi.org/10.1111/j.1745-6916.2007.00051.x

Berggren, N., Jordahl, H., \& Poutvaara, P. (2010). The looks of a winner: Beauty and electoral success. Journal of Public Economics, 94(1-2), 8-15. https://doi.org/10.1016/j.jpubeco.2009.11.002

Buss, D. M. (1989). Sex differences in human mate preferences: Evoluntionary hypotheses tested in 37 cultures. Behavioural and Brain Sciences, 12(1989), 1-14. https://doi.org/10.1017/S0140525X00023992

Dion, K., Berscheid, E., \& Walster, E. (1972). What is beautiful is good. Journal of Personality and Social Psychology, 24(3), 285-290. https://doi.org/10.1177/0956797610388048

Duarte, J., Siegel, S., \& Young, L. (2012). Trust and credit: The role of appearance in peer-topeer lending. Review of Financial Studies, 25(8), 2455-2483. https://doi.org/10.1093/rfs/hhs071

Eagly, A. H., Ashmore, R. D., Makhijani, M. G., \& Longo, L. C. (1991). What is beautiful is good, but...: A meta-analytic review of research on the physical attractiveness stereotype. Psychological Bulletin, 110(1), 109-128. https://doi.org/10.1037/0033-2909.110.1.109

Eckel, C. C., \& Petrie, R. (2011). Face value. The American Economic Review, 101(4), 14971513. https://doi.org/10.1257/aer.101.4.1497

Edelman, B., \& Luca, M. (2014). Digital Discrimination: The Case of Airbnb.com. Harvard Business School NOM Unit Working Paper No. 14-054. https://doi.org/https://ssrn.com/abstract=2377353 
Edelman, B., Luca, M., \& Svirsky, D. (2017). Racial discrimination in the sharing economy: Evidence from a field experiment. American Economic Journal: Applied Economics, 9(2), 1-22. https://doi.org/10.1257/app.20160213

Einav, L., Farronato, C., \& Levin, J. (2016). Peer-to-peer markets. Annual Review of Economics, 8(1), 615-635. https://doi.org/10.1146/annurev-economics-080315-015334

Ert, E., Fleischer, A., \& Magen, N. (2016). Trust and reputation in the sharing economy: The role of personal photos in Airbnb. Tourism Management, 55, 62-73. https://doi.org/10.1016/j.tourman.2016.01.013

Fagerstrøm, A., Pawar, S., Sigurdsson, V., Foxall, G. R., \& Yani-de-Soriano, M. (2017). That personal profile image might jeopardize your rental opportunity! On the relative impact of the seller's facial expressions upon buying behavior on Airbnb ${ }^{\mathrm{TM}}$. Computers in Human Behavior. https://doi.org/10.1016/j.chb.2017.02.029

Feingold, A. (1990). Gender differences in effects of physical attractiveness on romantic attraction: A comparison across five research paradigms. Journal of Personality and Social Psychology, 59(5), 981-993. https://doi.org/10.1037/0022-3514.59.5.981

Fiske, S. T., Cuddy, A. J. C., Glick, P., \& Xu, J. (2002). A model of (often mixed) stereotype content: Competence and warmth respectively follow from perceived status and competition. Journal of Personality and Social Psychology, 82(6), 878-902. https://doi.org/10.1037//0022-3514.82.6.878

Gheorghiu, A. I., Callan, M. J., \& Skylark, W. J. (2017). Facial appearance affects science communication. Proceedings of the National Academy of Sciences, (35), 201620542. https://doi.org/10.1073/pnas.1620542114

Gibbs, C., Guttentag, D., Gretzel, U., Morton, J., \& Goodwill, A. (2018). Pricing in the sharing economy: A hedonic pricing model applied to Airbnb listings. Journal of Travel and Tourism Marketing, 35(1), 46-56. https://doi.org/10.1080/10548408.2017.1308292

Gonzalez, L., \& Loureiro, Y. K. (2014). When can a photo increase credit? The impact of lender and borrower profiles on online peer-to-peer loans. Journal of Behavioral and Experimental Finance, 2, 44-58. https://doi.org/10.1016/j.jbef.2014.04.002

Guttentag, D. (2013). Airbnb: Disruptive innovation and the rise of an informal tourism accommodation sector. Current Issues in Tourism, 37-41. https://doi.org/10.1080/13683500.2013.827159 
Hamermesh, D. S., \& Biddle, J. E. (1994). Beauty and the labor market. The American Economic Review, 84(5), 1174-1194. https://doi.org/10.1016/B978-0-08-097086-8.94015-7

Hehman, E., Sutherland, C. A. M., Flake, J. K., \& Slepian, M. L. (2017). The unique contributions of perceiver and target characteristics in person perception. Journal of Personality and Social Psychology, 113(4), 513-529. https://doi.org/10.1037/pspa0000090

Hehman, E., Xie, S. Y., Ofosu, E. K., \& Nespoli, G. A. (2018). Assessing the point at which averages are stable: A tool illustrated in the context of person perception. Retrieved from https://psyarxiv.com/2n6jq/

Heyes, A., \& List, J. A. (2016). Supply and demand for discrimination: Strategic revelation of own characteristics in a trust game. American Economic Review, 106(5), 319-323. https://doi.org/10.1257/aer.p20161011

Jaeger, B., Sleegers, W. W. A., \& Evans, A. M. (2018). Automated classification of demographics from face images: A tutorial and validation. Retrieved from https://psyarxiv.com/8pv4q/

Jaeger, B., Wagemans, F. M. A., Evans, A., \& van Beest, I. (2018). The effects of facial skin smoothness and blemishes on trait impressions. Perception, 1-18. https://doi.org/10.1177/0301006618767258

Kakar, V., Franco, J., Voelz, J., \& Wu, J. (2016). The visible host: Does race guide Airbnb rental rates in San Francisco? Retrieved from https://mpra.ub.uni-muenchen.de/78275/

Klapper, A., Dotsch, R., van Rooij, I., \& Wigboldus, D. H. J. (2016). Do we spontaneously form stable trustworthiness impressions from facial appearance? Journal of Personality and Social Psychology, 111(5), 655-664. https://doi.org/10.1037/pspa0000062

Kosinski, M. (2017). Facial width does not predict self-reported behavioral tendencies. Psychological Science, 28(11), 1675-1682. https://doi.org/10.1177/0956797617716929

Ma, X., Hancock, J. T., Mingjie, K. L., \& Naaman, M. (2017). Self-disclosure and perceived trustworthiness of Airbnb host profiles. In Proceedings of the 2017 ACM Conference on Computer Supported Cooperative Work and Social Computing (CSCW'17) (pp. 23972409). New York, NY. https://doi.org/10.1145/2998181.2998269 
Maestripieri, D., Henry, A., \& Nickels, N. (2017). Explaining financial and prosocial biases in favor of attractive people: Interdisciplinary perspectives from economics, social psychology, and evolutionary psychology. Behavioral and Brain Sciences, 40, e19. https://doi.org/10.1017/S0140525X16000340

Malpezzi, S. (2008). Hedonic pricing models: A selective and applied review. In T. O'Sullivan \& K. Gibb (Eds.), Housing Economics and Public Policy. Sage Publications, Inc.

Maner, J. K. (2016). Into the wild: Field research can increase both replicability and real-world impact. Journal of Experimental Social Psychology, 66, 100-106. https://doi.org/10.1016/j.jesp.2015.09.018

Megvii Inc. (2018). Face++ (Computer software). Retrieved from http://www.faceplusplus.com.

Olivola, C. Y., Funk, F., \& Todorov, A. (2014). Social attributions from faces bias human choices. Trends in Cognitive Sciences, 18(11), 566-70. https://doi.org/10.1016/j.tics.2014.09.007

Olivola, C. Y., \& Todorov, A. (2010). Fooled by first impressions? Reexamining the diagnostic value of appearance-based inferences. Journal of Experimental Social Psychology, 46(2), 315-324. https://doi.org/10.1016/j.jesp.2009.12.002

Oosterhof, N. N., \& Todorov, A. (2008). The functional basis of face evaluation. Proceedings of the National Academy of Sciences, 105(32), 11087-11092. https://doi.org/10.1073/pnas.0805664105

Pazda, A. D., Thorstenson, C. A., Elliot, A. J., \& Perrett, D. I. (2016). Women's facial redness increases their perceived attractiveness: Mediation through perceived healthiness. Perception, 45(7), 739-754. https://doi.org/10.1177/0301006616633386

Penton-Voak, I. S., Pound, N., Little, A. C., \& Perrett, D. I. (2006). Personality judgments from natural and composite facial images: More evidence for a "kernel of truth" in social perception. Social Cognition, 24(5), 607-640. https://doi.org/10.1521/soco.2006.24.5.607

Ravina, E. (2012). Love \& loans: The effect of beauty and personal characteristics in credit markets. https://doi.org/http://dx.doi.org/10.2139/ssrn.1101647

Rhodes, G. (2006). The evolutionary psychology of facial beauty. Annual Review of Psychology, 57, 199-226. https://doi.org/10.1146/annurev.psych.57.102904.190208 
Rhodes, G., Yoshikawa, S., Palermo, R., Simmonsá, L. W., Peters, M., Lee, K., .. Crawford, J. R. (2007). Perceived health contributes to the attractiveness of facial symmetry, averageness, and sexual dimorphism. Perception, 36, 1244-1253. https://doi.org/10.1068/p5712

Rhue, L., \& Clark, J. (2016). Who gets started on Kickstarter? Racial disparities in crowdfunding success. https://doi.org/10.2139/ssrn.2837042

Ritchie, K. L., Palermo, R., \& Rhodes, G. (2017). Forming impressions of facial attractiveness is mandatory. Scientific Reports, 7(469), 1-8. https://doi.org/10.1038/s41598-017-00526-9

Rosen, S. (1974). Hedonic prices and implicit markets: Product differentiation in pure competition. Journal of Political Economy, 82(1), 34-55. https://doi.org/10.1086/260169

Rule, N. O., Krendl, A. C., Ivcevic, Z., \& Ambady, N. (2013). Accuracy and consensus in judgments of trustworthiness from faces: Behavioral and neural correlates. Journal of Personality and Social Psychology, 104(3), 409-26. https://doi.org/10.1037/a0031050

Schaller, M., \& Duncan, L. A. (2007). The Behavioral Immune System. In J. P. Forgas, M. G. Haselton, \& W. von Hippel (Eds.), The Handbook of Evolutionary Psychology (pp. 293307). New York: Psychology Press. https://doi.org/10.1002/9781119125563.evpsych107

Simonsohn, U. (2015). Small telescopes: Detectability and the evaluation of replication results. Psychological Science, 26(5), 559-569. https://doi.org/10.1177/0956797614567341

Sutherland, C. A. M., Liu, X., Zhang, L., Chu, Y., Oldmeadow, J. A., \& Young, A. (2017). Facial first impressions across culture: data-driven modelling of Chinese and British perceivers' unconstrained facial impressions. Personality and Social Psychology Bulletin. https://doi.org/10.1177/0146167217744194

Sutherland, C. A. M., Oldmeadow, J. A., Santos, I. M., Towler, J., Michael Burt, D., \& Young, A. W. (2013). Social inferences from faces: Ambient images generate a three-dimensional model. Cognition, 127(1), 105-118. https://doi.org/10.1016/j.cognition.2012.12.001

Sutherland, C. A. M., Oldmeadow, J. A., \& Young, A. W. (2016). Integrating social and facial models of person perception: Converging and diverging dimensions. Cognition, 157, 257267. https://doi.org/10.1016/j.cognition.2016.09.006

Sutherland, C. A. M., Young, A. W., \& Rhodes, G. (2016). Facial first impressions from another angle: How social judgements are influenced by changeable and invariant facial properties. British Journal of Psychology, 1-19. https://doi.org/10.1111/bjop.12206 
Todorov, A., Olivola, C. Y., Dotsch, R., \& Mende-Siedlecki, P. (2015). Social attributions from faces: Determinants, consequences, accuracy, and functional significance. Annual Review of Psychology, 66(1), 519-545. https://doi.org/10.1146/annurev-psych-113011-143831

Todorov, A., \& Porter, J. M. (2014). Misleading first impressions: Different for different facial images of the same person Suppemental Material. Psychological Science, 25(7), 14041417. https://doi.org/10.1177/0956797614532474

Wang, D., Xi, S., \& Gilheany, J. (2015). The model minority? Not on Airbnb.com: A hedonic pricing model to quantify racial bias against Asian Americans. Technology Science. Retrieved from http://techscience.org/a/2015090104/\#Suggestions

Wedel, M., \& Pieters, R. (2007). A review of eye-tracking research in marketing. Review of Marketing Research, 4, 123-147. https://doi.org/10.1108/S1548-6435(2008)0000004009

Willis, J., \& Todorov, A. (2006). First impressions: Making up your mind after a 100-ms exposure to a face. Psychological Science, 17(7), 592-598. https://doi.org/10.1111/j.14679280.2006.01750.x

Zebrowitz, L. A., Fellous, J. M., Mignault, A., \& Andreoletti, C. (2003). Trait impressions as overgeneralized responses to adaptively significant facial qualities: evidence from connectionist modeling. Personality and Social Psychology Review, 7(3), 194-215. https://doi.org/10.1207/S15327957PSPR0703_01

Zebrowitz, L. A., \& Rhodes, G. (2004). Sensitivity to "bad genes" and the anomalous face overgeneralization effect: Cue validity, cue utilization, and accuracy in judging intelligence and health. Journal of Nonverbal Behavior, 28(3), 167-185. https://doi.org/10.1023/B:JONB.0000039648.30935.1b 